\title{
Tourist of The North Portugal Region and Local Accommodation: Influences and Motivations
}

\author{
Teresa Dieguez ${ }^{1}$ and Fernanda A. Ferreira ${ }^{2}$ \\ ${ }^{1}$ Polytechnic Institute of Porto, School of Hospitality and Tourism, CiTUR, Vila do Conde, Portugal \\ ${ }^{2}$ Polytechnic Institute of Porto, School of Hospitality and Tourism, Applied Management Research Unit \\ (UNIAG), Vila do Conde, Portugal
}

Correspondence should be addressed to: Teresa Dieguez; teresadiegez@esht.ipp.pt

Received date: 28 April 2020; Accepted date: 23 July 2020; Published date: 30 September 2020

Academic Editor: Attila TURI

Copyright (c) 2020. Teresa Dieguez and Fernanda A. Ferreira. Distributed under Creative Commons Attribution 4.0 International CC-BY 4.0

\begin{abstract}
Local Accommodation is increasingly an option for those who travel and seek new concepts or follow trends. The present research aims to understand what the main influence and motivation factors are when the tourist of the north Portugal chooses local accommodation in Portugal and abroad. After a literature review, an online survey was conducted during May and July 2019, with all Portuguese living in the north of Portugal who had travelled at least once over the past 5 years. A random sample of 239 participants was collected and data was treated through SPSS software. The gathered information allowed developing an exploratory descriptive analysis, an inferential analysis and a factor analysis. The results seem to indicate that there is a significant relationship between the national tourist's adhesions to touristic accommodation in Portugal and abroad. The adhesion to local accommodation in Portugal is not associated with the reasons for the trip/travel, and the adhesion to local accommodation abroad is mostly motivated by leisure. The location (Portugal/abroad) is not relevant to the perception of the national tourist about the touristic accommodation.
\end{abstract}

Keywords: Local Accommodation, Influences, Motivations, Tourism, Touristic Accommodation.

Cite this Article as: Teresa Dieguez and Fernanda A. Ferreira (2020)," Tourist of The North Portugal Region and Local Accommodation: Influences and Motivations ", IBIMA Business Review, Vol. 2020 (2020), Article ID 989975, DOI: $10.5171 / 2020.989975$ 


\section{Introduction}

Tourism is a social, cultural and economic phenomenon which involves the movement of people to countries or places outside their usual environment for personal or business/professional purposes (Sharpley, 2014; UNWTO, 2018). When studying tourism, motivation and experience of tourists, expectations and adjustments on the destination community and related stakeholders must be considered. People's lives comprise foreign and domestic tourism (Chang \& Katrichis, 2016) and when they are travelling, they want to find innovative tourism products, designed with quality (Kisi, 2019), satisfying their needs and expectations, and increasing their intentions of return and loyalty as well (Mwinuka, 2017). Tourism is a strategic sector, considered as the most important economic factor of the social and economic development in the world (Weaver \& Lawton, 2010), with an unavoidable and transversal impact on several sectors, creating jobs and wealth (UNTWO, 2020). Representing over than $10 \%$ of the global GDP, it is the second-fastest growing industry in attracting Foreign Direct Investments, and it is the second-largest job creator, supporting 292 million jobs by the end of 2016 (International Finance Corporation, 2017). Digital platforms in the travel and tourism industry are increasingly used, both by travelers and by businesses engaged in the industry (Lopez-Cordova, 2020), and the applied technology is achieving results that exceed people's expectations, allowing big connections, exchange of information and achievement of results in real time (International Tourism Highlights, 2019 Edition, 2019). In Portugal, the tourism sector is the largest export economic activity in the country, being responsible, in 2019, for $52.3 \%$ of the exports of services and for $19.7 \%$ of the total exports, with tourism revenues registering a contribution of $8.7 \%$ in the Portuguese GDP (Turismo de Portugal, 2020). The Northern Region of Portugal (NUTS 2) accounts for $23 \%$ of the country's total surface area and approximately $35 \%$ of the national resident population. This region contains $18.4 \%$ of the Local Accommodation units of Portugal, clearly highlighting the district of Porto, with $69.4 \%$ of the units in this region (INE, 2018). The promotion of tourism in the North as a whole is based on the following strategic products: i) business tourism; ii) city breaks; iii) gastronomy and wine; iv) health tourism; v) heritage; vi) nature tourism; vii) religious tourism and vii) touring and cultural landscape (Oliveira, 2014). New patterns and new profiles of tourists appear, requiring research in order to analyze whether the evolution of tourism and the new forms of accommodation accompany the needs of the Portuguese tourist. The present study aims to understand the perception of the national tourist in relation to the local accommodation in Portugal and abroad, and also to understand what motivates and influences them, when choosing accommodation while travelling.

\section{Literature Review}

\section{Tourism}

In 2019, Travel \& Tourism's direct, indirect and induced impact accounted for: US $\$ 8.9$ trillion contribution to the world's GDP, $10.3 \%$ of the global GDP, 330 million jobs, 1 in 10 jobs around the world, US\$1.7 trillion visitors' exports $(6.8 \%$ of the total exports, $28.3 \%$ of the global services exports) and US $\$ 948$ billion capital investment $(4.3 \%$ of the total investment). 2019 was another year of strong growth for the global Travel \& Tourism sector, reinforcing its role as a driver of economic growth and job creation (WTTC, 2020). The concept has evolved over the past few decades, and nowadays it is considered as a decisive link in accelerating the pace of the global socioeconomic development (Joseph, 2013). It has different meanings for different people (Pruthi, 2004) and may be seen as the total sum of phenomena and dealings activated from trips and stays of non-residents, insofar as they do 
not lead to permanent residence and are not linked to any earning activity (Robison, 1976). When analysing tourism, a more holistic approach is crucial and should include all the key characteristics of it, namely transport, stay and activities at destination, as well as movement of people demand's and supply's determinants (Leslie, 2000). Tourism is influenced by the destination itself, and destination encompasses the regions, countries, cities and other areas that attract tourists. Nevertheless, tourism has great impacts on the touristic destinations, namely sociocultural, economic and environmental impacts (Chetthamrongchai, 2017).

\section{Collaborative Economy}

The concept of a collaborative economy is broadly studied in the literature and it has several interpretations, often appearing as a sharing economy or a collaborative consumption (Botsman \& Rogers, 2010). Collaborative economy is an economic system of decentralised networks and marketplaces that unlocks the value of underused assets by matching needs and haves, in ways that bypass traditional middlemen (Botsman, 2015). Collaborative consumption is a system in which consumers enjoy a certain good without actually owning it (Lamberton \& Rose, 2012). The collaborative economic system has three broad characteristics and is linked with the access to products or services without the need to own the underlying assets, the reallocation of goods and the exchange of intangible assets (Botsman \& Roger, 2010). It is built on individual or community knowledge networks versus centralized institutions (Botsman \& Rogers, 2010) and can be defined in four dimensions: i) collaborative production, ii) collaborative consumption, iii) collaborative financing and iv) collaborative education. In essence, collaborative economy is based on transactions that happen between businessto-business (B2B), business-to-consumer (B2C) and peer-to-peer (P2P), where the contact between the service provider and the final consumer is established through a digital and online medium (Botsman \& Rogers, 2010). The collaborative economy uses the internet to match people who want to share assets and services (Petropoulos, 2017), and some examples of the collaborative economy platforms are 9flats, Airbnb, Roomorama and Stayz, among others (Mahadevan, 2018). In recent years, the local accommodation market has been growing sharply, and this new economic concept presents the Airbnb platform as a leader in the local accommodation market (Mahadevan, 2018) with more than 2 million properties spreading across the world (Airbnb, 2015). Although there is no consensus, researchers like Zervas et al. (2017) defend that the existence of platforms such as Airbnb that provide low-cost accommodation, encourage tourism and the consequent increase in the number of travellers, as well as opportunities for new jobs. On the other hand, some other researchers argue that the impact is low or null (Haywood, Wilson, Hennis \& Alvarado, 2016; Wroten, 2017).

\section{Consumer Psychology}

Consumer psychology deals with the way individuals or groups are involved in consumer activities and the effect it has on them personally. For this reason, it is quite difficult to understand consumer psychology without having an understanding of the ways individuals process information and make decisions (Vainikka, 2015). Extensive research of consumer psychology highlighted the underlying aspects of individuals that make up consumer engagement. Consumer psychology is the scientific study of the behaviour of consumers (Mullen \& Johnson, 1990, p. 1). Foxall (1990) and Foxall \& Goldsmith (1994) emphasize the significance of the cognitive consumer as a basis for this scientific understanding of consumer behaviour that "consumer choice is portrayed as an ego-involving sequence of cognitive and affective changes which precede and predetermine the purchase/no purchase outcome" (Foxall, 1990, p. 9). The 
practice of tourism is entirely related to the act of meeting new people, sharing customs and cultures that can often result in conflicts between tourists, and also between tourists and inhabitants of the visited places (Šimková, 2014). it is crucial to understand the factors that influence consumer behaviour when choosing a product or service, subdividing them into 6 different steps according to their acquisition: i) the recognition of the need, ii) the search for information, iii) the alternative assessment, iv) the acquisition, v) the post-acquisition assessment and vi) the divestment (Blythe, 2005). These steps have the presence of cultural, social, personal and psychological factors that determine the choice of a product/service over another (Kotler, 2000; Kotler \& Amstrong, 2011). In the light of the above, it seems possible to argue that the competitiveness of a destination depends largely on the experience that the tourist had in that same destination (Pavlovic, 2016).

\section{Motivations and Influences When Choosing Accommodation}

For tackling the hotel establishments scarcity in times of great affluence and events in cities, new types of accommodation inserted in a collaborative economy have emerged (Bardhi \& Eckhardt, 2012; Botsman \& Rogers, 2010), becoming major competitors of hotel establishments and the services they provide (Freitag \& Haywood, 2015). Consumers may have lots of reasons for doing that, but the main reason seems to be the one linked with monetary benefits (Bellotti et al., 2015; Botsman \& Rogers, 2010; Möhlmann, 2015; Sacks, 2011). Other factors can be added like good quality services, amenities and location (Tussyadiah \& Zach, 2015), reduction of environmental impacts and relationship with communities (Botsman \& Rogers, 2010; Gansky, 2012), social needs (Botsman \& Rogers, 2010; Möhlmann, 2015) and sustainability and authenticity (Hamari, Sjöklint \& Ukkonen, 2016). In fact, authenticity and the sharing of new cultures are something that is in high demand (Lewis \& Bridger, 2000) and local accommodations such as hostels and "Airbnb" highlight those concepts. The behaviours of tourists are changing. When a tourist stays in a private and local housing, he tends to stay more nights, spend more money and travel more frequently (Tussyadiah \& Pesonen, 2015). Larger hotel establishments need to adapt their services to this new reality (Byers, Proserpio \& Zervas, 2013) and these new accommodations are seen as places where tourists have the opportunity to make new friends, creating connections that can stay for life (Botsman \& Rogers, 2010), socially interact with the host of the accommodation and have an opportunity to explore places that are outside the conventional routes (Guttentag, 2015). Local accommodations also allow being in contact with historical landmarks which is an important mechanism to experience the authenticity of the heritage (Chhabra, Healy \& Sills, 2003).

\section{Research Questions, Hypotheses and Methodology}

The main objective of this research is to understand what the main influence and motivation factors are when the tourist of the north Portugal chooses local accommodation in Portugal and abroad. The secondary objectives are focused on: i) describing the motivations of the national tourist in the North region when travelling in Portugal and abroad, considering chosen accommodation type, ii) relating possible influences, iii) finding differences and relationships in the search for local accommodation and touristic accommodation in Portugal and abroad.

Therefore, the defined Research Hypotheses $(\mathrm{RH})$ are as follows:

- RH1 - The adhesion of national tourists to local accommodation abroad is related to the adhesion to local accommodation in Portugal.

- $\quad$ RH2 - The adhesion of the national tourist to touristic accommodation 
abroad is related to the adhesion to touristic accommodation in Portugal.

- RH3 - The adhesion to local accommodation in Portugal is related to the motivations of the trip.

- RH4 - The adhesion to local accommodation abroad is related to the motivations of the trip.

The research used a quantitative methodology and applied a questionnaire survey designed within the scope of the studied literature review. The survey questions were all closed-ended and the survey included dichotomous, multiplechoice and rank order questions, as well as Likert-type scales in a five-point scale of agreement (from 1-Strongly disagree to 5Strongly agree) and of frequency (from 1 Never to 5 - Always). Between May and July 2019 , a random sample was collected from national tourists, over 18 years old, inhabiting Porto and north of Portugal, who had travelled at least once in the last 5 years in Portugal or abroad. The questionnaire was conducted through the Limesurvey and distributed to a list of more than 5,000 personal e-mails. It was also publicised through different social media as Linkedin and Facebook. A total of 239 of the collected questionnaires were considered valid, representing a sampling error of 6,3\%, assuming a $95 \%$ accuracy level.

The questionnaire was divided into three sections, namely: i) information about the respondents: supporting the relation between the components of the individual profile and local accommodation; ii) characterization of the respondents: according to what motivated them to travel in Portugal and where, a question based on 14 items was applied, aiming to identify the greatest motivations for travelling in Portugal in the last 5 years, iii) understanding what type of accommodation respondents looked for the most in Portugal in the last 5 years, with a question about the how often they stayed in local accommodation in Portugal in the last 5 years and another question about how often they stayed in touristic accommodation in Portugal in the last 5 years. All questions from section two and three are repeated in sections four and five, but specifically for respondents when travelling abroad. The collected data was treated through the SPSS software. The exploratory descriptive statistical analysis allows to study the observed characteristics, as well as to analyse the main influences on the choice of accommodation, in Portugal and abroad, and the motivations while travelling.

To analyse the validity of the hypotheses of the research, an inferential analysis was chosen and different tests were used to confirm or refute the hypotheses of investigation. The chi-squared independence test allowed to understand whether or not there is a significant relationship between two or more categorical variables, and the non-parametric Mann-Whitney $U$ test allowed to compare the differences between two independent groups. The considered level of significance throughout the analysis was $5 \%$. To uncover the underlying structure of a set of variables, the research applied a factorial analysis, a multivariate statistical method, with the purpose of identifying the key factors that determine the motivations for tourists to travel in Portugal and abroad. To check the reliability of the questionnaire, the internal consistency was analysed using Cronbach's Alpha coefficient.

\section{Results and Analysis}

\section{Sample Characteristics}

The respondents were mainly females (58.2\%) (Figure 1). They are mostly 18-35 years old $(71.9 \%)$ and only $8.0 \%$ of the respondents are above 65 years (Figure 2). Their level of education is high, being bachelors (49.4\%), masters (22.6\%), and PhDs (3.3\%) (Figure 3). About $40.6 \%$ of the respondents have a monthly net income between $501 €-1,000 €$, and $24.3 \%$ between $1,001 €-2,000 €$. However, $15.5 \%$ of the respondents have incomes less than €500 monthly, and only $10.1 \%$ have more than 


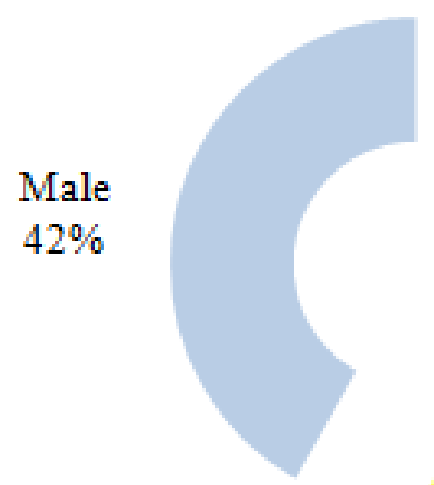

Female $58 \%$

Source: Own elaboration
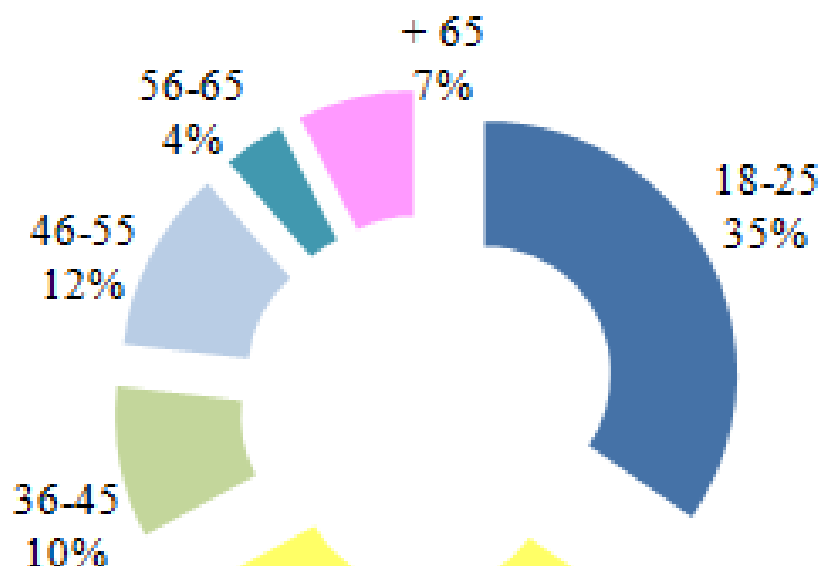

26-35

$32 \%$

Source: Own elaboration

Figure 2: Age of respondents 


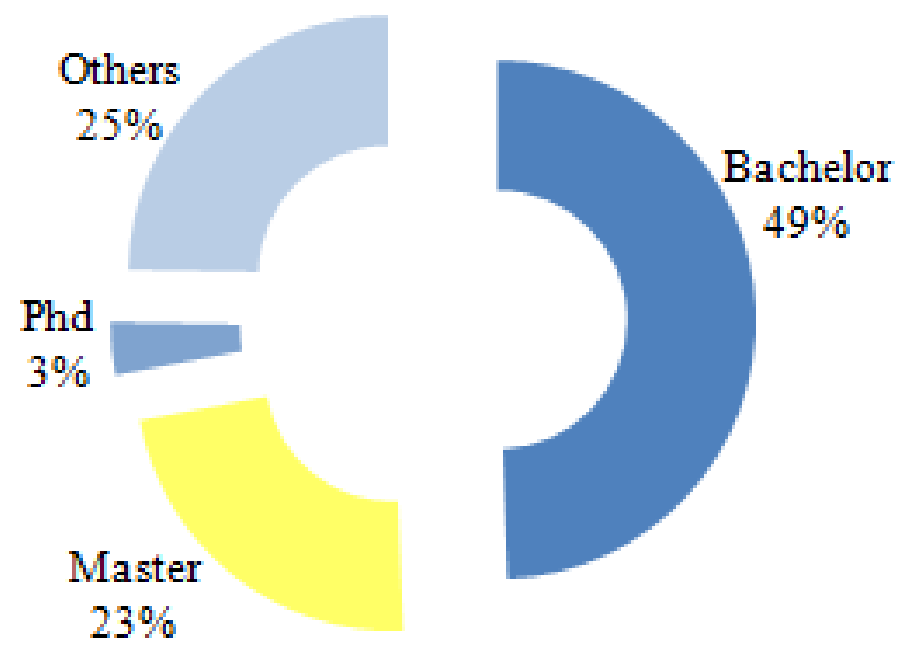

Source: Own elaboration

Figure 3: Respondents' level of education

Respondents are mostly single (66.5\%) between 18 and 25 years old, and $89.2 \%$ (Figure 4) and do not have children (98.9\% between 26 and 35 years old).

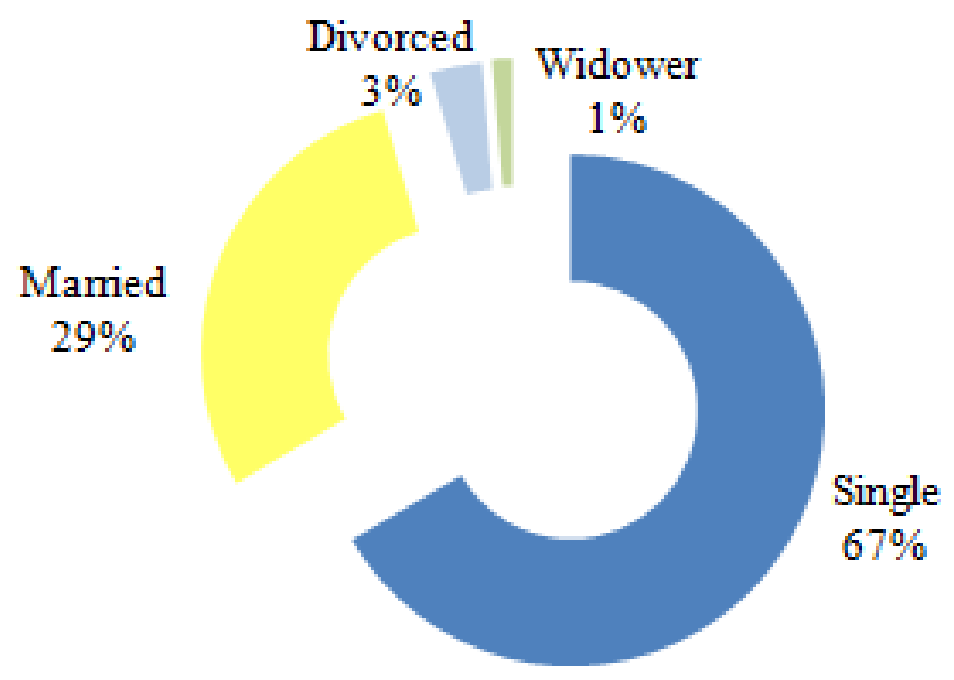

Source: Own elaboration

Figure 4: Respondents' marital status

All respondents live in the North of Portugal, comprising 8 sub-regions or level III units (NUTS III). The majority, $70.2 \%$, live in the metropolitan area of Porto, $11.8 \%$ in Braga and the remaining $18 \%$ in the remaining subregions.

The frequencies of accommodation in local accommodation in Portugal and abroad are 
represented in Figure 5. The values indicate that 113 of 233 respondents (48.5\%) did not stay in local accommodation in Portugal, and 110 of 212 (51.9\%) have not stayed in local accommodation abroad. 120 of the respondents (51.5\%) stayed in local accommodation in Portugal, and 102 (48.1\%) in local accommodation abroad. The data indicate that the percentage of individuals who did not stay in local accommodation in
Portugal is close to the percentage of individuals who did not stay in local accommodation abroad, with the same trend for those who have already stayed in local accommodation in Portugal and abroad. This means that a higher percentage value of the sample under study chose to stay in local accommodation in Portugal, in contrast to when travelling abroad

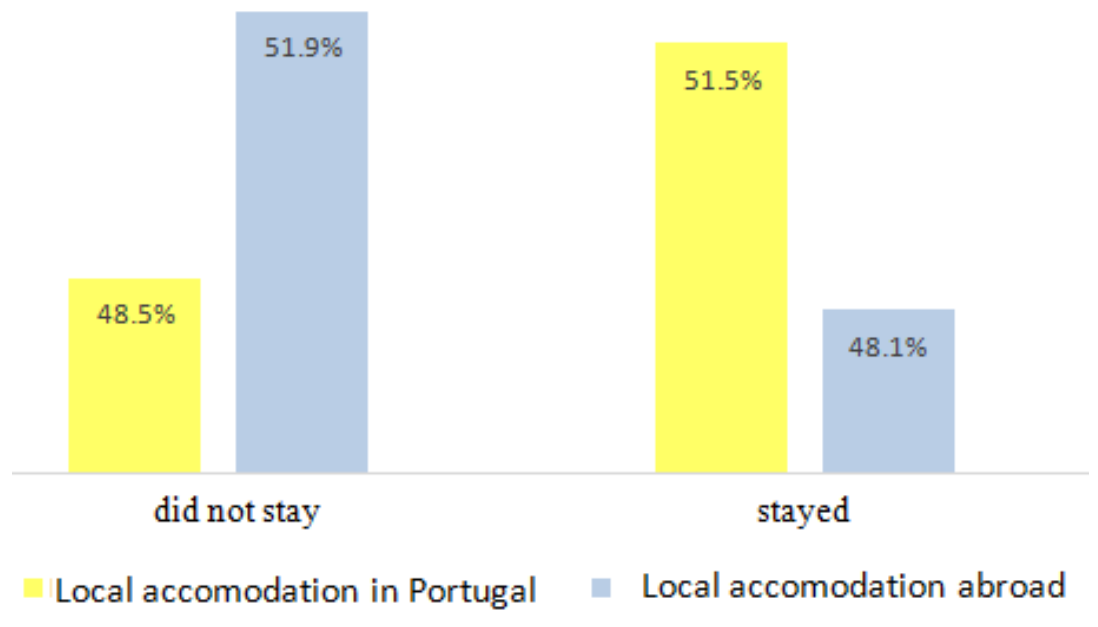

Figure 5: Frequency of accommodation in local accommodation in Portugal and abroad Source: Own elaboration

Comparing the frequency of accommodation between touristic accommodation and local accommodation in Portugal, there were significant differences in their adherence. In fact, in Portugal, only 47 (20.2\%) of the respondents did not stay in touristic accommodation, while $48.5 \%$ did not stay in local accommodation. Figure 6 shows the comparison between those who have stayed and those who have not stayed in local accommodation and touristic accommodation in Portugal. 


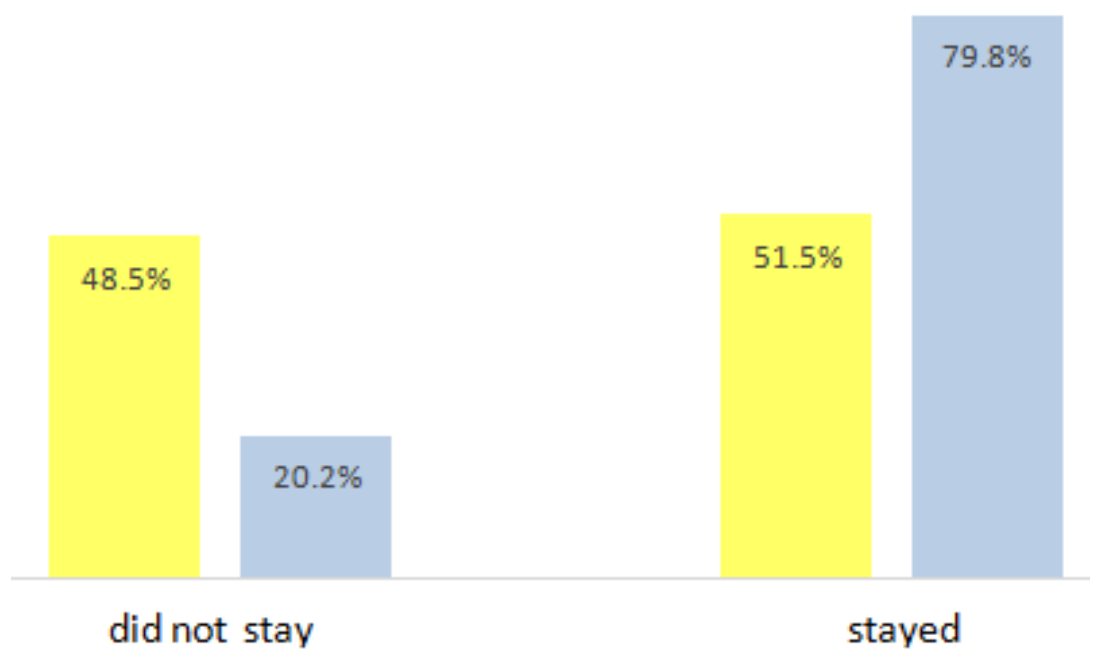

Figure 6: Frequency of accommodation in local accommodation and in touristic accommodation in Portugal

Source: Own elaboration

Concerning those who have stayed and those who have not stayed in local accommodation and in touristic accommodation abroad, only $24.1 \%$ of the respondents didn't stay in touristic accommodation, while $51.9 \%$ didn't stay in local accommodation.

Regarding the factors that the national tourist from the North most valued when staying in local accommodation in Portugal, the price stood out with $43.4 \%$, followed by hospitality $(23.4 \%)$ and then location (6.6\%). Those are the same most valued factors when travelling abroad, as the price also stood out with (44.3\%) and location (31.7\%), followed by facilities and support conditions, with $28.6 \%$. The study seems to point out that the most valued factors by the national tourist in the northern zone are very similar when looking for local accommodation in Portugal and abroad. An attractive price and a favourable location of the accommodation at the destination place largely influence the adhesion to the local accommodation. In fact, price was chosen as the main factor that influences the national tourist from the North to stay in local accommodation in Portugal and abroad. This is supported by other studies, evidenced in the bibliographic reviewby Hamari, Sjöklint \& Ukkonen (2016), Möhlmann (2015), Botsman \&
Rogers (2010), Gansky (2012), Tussyadiah \& Zach (2015), Guttentag (2015), Bellotti et al. (2015), Lamberton \& Rose (2012) and Sacks (2011). As opposed to what happened with the price, authenticity was the least valued factor in the choice of local accommodation in Portugal and abroad, by the national tourist. This result highlights non concordance with what was previously mentioned in the literature review by Bardhi \& Eckhardt (2012), Botsman \& Rogers (2010), Gansky (2012) and Hamari, Sjöklint \& Ukkonen (2016). It seems to demonstrate the existence of some conservatism as well as the weight of cultural values in the Portuguese society (Kotler, 2000), making it impossible for individuals to live the experience in an authentic way.

Concerning the motivations for the national tourist in the northern zone to travel in Portugal and abroad, the study shows that in a general way, they feel motivated to travel, presenting an average of 3.60 for Portugal and 3.39 for abroad, on a scale from 1-5. Table 1 shows the obtained percentages for each of the variables by levels of satisfaction, for Portugal (P) and for other countries (0), as well as the average degree of satisfaction and the standard deviation. 
Table 1: Motivations for the national tourist to travel in Portugal and abroad

\begin{tabular}{|c|c|c|c|c|c|c|c|c|c|c|c|c|}
\hline \multirow{2}{*}{$\begin{array}{c}\text { Level of satisfaction } \\
\text { Item }\end{array}$} & \multicolumn{2}{|c|}{1} & \multicolumn{2}{|c|}{2} & \multicolumn{2}{|c|}{3} & \multicolumn{2}{|c|}{4} & \multicolumn{2}{|c|}{5} & \multicolumn{2}{|c|}{ Mean \pm SD } \\
\hline & \begin{tabular}{l|l|}
$\mathrm{P}$ \\
$\%$ \\
\end{tabular} & $\begin{array}{l}\mathrm{O} \\
\% \\
\end{array}$ & $\begin{array}{l}\mathrm{P} \\
\% \\
\end{array}$ & $\begin{array}{l} \\
\% \\
\end{array}$ & $\begin{array}{l}\mathrm{P} \\
\% \\
\end{array}$ & $\begin{array}{l}\mathrm{O} \\
\% \\
\end{array}$ & $\begin{array}{l}\mathrm{P} \\
\% \\
\end{array}$ & $\begin{array}{l}0 \\
\%\end{array}$ & $\begin{array}{l}\mathrm{P} \\
\% \\
\end{array}$ & $\begin{array}{l}0 \\
\% \\
\end{array}$ & $\mathrm{P}$ & $\mathrm{O}$ \\
\hline Price & 9.4 & 6.6 & 6.9 & 17.9 & 24.9 & 26.4 & 40.3 & 31.1 & 18.5 & 17.9 & $3.52 \pm 1.15$ & $3.36 \pm 1.16$ \\
\hline History/Culture & 4.3 & 1.9 & 6.9 & 1.9 & 16.7 & 10.8 & 45.1 & 38.7 & 27.0 & 46.7 & $3.84 \pm 1.04$ & $4.26 \pm 0.87$ \\
\hline Acommodation & 6.4 & 6.6 & 6.0 & 17.9 & 27.5 & 39.2 & 43.3 & 23.6 & 16.7 & 12.7 & $3.58 \pm 1.04$ & $3.18 \pm 1.08$ \\
\hline Gastronomv & 5.2 & 9.9 & 5.6 & 13.7 & 18.0 & 38.2 & 38.6 & 26.4 & 32.6 & 11.8 & $3.88 \pm 1.09$ & $3.17 \pm 1.12$ \\
\hline Hospitality & 5.2 & 7.1 & 4.7 & 11.3 & 15.0 & 42.5 & 42.5 & 29.7 & 32.6 & 9.4 & $3.93 \pm 1.06$ & $3.23 \pm 1.01$ \\
\hline Sun and beach conditions & 3.4 & 9.9 & 1.7 & 10.4 & 14.6 & 25.9 & 39.5 & 25.9 & 40.8 & 27.8 & $4.12 \pm 0.96$ & $3.51 \pm 1.27$ \\
\hline $\begin{array}{l}\text { Accessibility \& ease of } \\
\text { travel }\end{array}$ & 2.6 & 4.2 & 1.7 & 7.1 & 11.6 & 25.5 & 35.6 & 40.6 & 48.5 & 22.6 & $4.26 \pm 0.92$ & $3.7 \pm 1.03$ \\
\hline tru's safety & 3.4 & 4.2 & 1.7 & 7.5 & 11.6 & 28.8 & 31.3 & 36.8 & 51.9 & 22.6 & $4.27 \pm 0.97$ & $3.66 \pm 1.04$ \\
\hline Attra & 3.0 & 6.1 & 1.3 & 6.1 & 9.9 & 21.2 & 45.1 & 39.6 & 40.8 & 26.9 & $4.19 \pm 0.89$ & $3.75 \pm 1.11$ \\
\hline Search for a dventure & 10.3 & 11.8 & 14.2 & 6.6 & 38.6 & 25.5 & 27.0 & 27.8 & 9.9 & 28.3 & $3.12 \pm 1.10$ & $3.54 \pm 1.29$ \\
\hline Healthreasons & 34.8 & 49.1 & 26.6 & 22.6 & 24.9 & 22.2 & 9.9 & 3.3 & 3.9 & 2.8 & $2.21 \pm 1.14$ & $1.88 \pm 1.04$ \\
\hline $\begin{array}{l}\text { Need (work, visiting family, } \\
\text { an/or business }\end{array}$ & 29.6 & 38.2 & 18.9 & 15.1 & 21.0 & 23.1 & 21.0 & 15.6 & 9.4 & 8.0 & $2.62 \pm 1.35$ & $2.40 \pm 1.34$ \\
\hline Attractive airline prices & 30.0 & 7.1 & 13.3 & 4.2 & 30.5 & 16.5 & 17.6 & 38.7 & 8.6 & 33.5 & $2.61 \pm 1.31$ & $3.87 \pm 1.14$ \\
\hline Nature/Landscape & 2.6 & 4.7 & 0.9 & 4.2 & 14.2 & 13.7 & 39.5 & 41.0 & 42.9 & 36.3 & $.19 \pm 0.90$ & $4.00 \pm 1.05$ \\
\hline
\end{tabular}

Source: Own elaboration

\section{Analysis of Research Hypotheses}

The previous presented hypotheses of the research were obtained through nonparametric tests. Responses for joining local accommodation and joining touristic accommodation were grouped into two groups: No (1-never; 2-rarely) and Yes (3- sometimes, 4-often and 5-always). The results of the chi-squared independent test (Table 2) suggest that there is a significant relationship between the national tourist's adhesion to local accommodation abroad with the adhesion to local accommodation in Portugal $(p<0.001)$ (RH1).

Table 2: Chi-squared independent test

\begin{tabular}{|c|c|c|c|c|}
\hline & & \multicolumn{2}{|c|}{$\begin{array}{l}\text { Local Housing Accommodation } \\
\text { abroad }\end{array}$} & \multirow[b]{2}{*}{$\mathrm{p}$-value } \\
\hline & & Not Hosted n(\%) & Hosted $\mathrm{n}(\%)$ & \\
\hline \multirow{2}{*}{$\begin{array}{l}\text { Local Housing } \\
\text { Accommodation in Portugal }\end{array}$} & Not Hosted & $68(69.4 \%)$ & $30(30.6 \%)$ & \multirow{2}{*}{$<0.001$} \\
\hline & Hosted & $40(37.0 \%)$ & $68(63.0 \%)$ & \\
\hline
\end{tabular}

Source: Own elaboration based on SPSS output ( $N=206$, due to omitted cases)

The results of the chi-squared independent test allow to concluded (RH2) that there is a significant relationship between the national tourist's adhesion to touristic accommodation in Portugal with the national adhesion to touristic accommodation abroad $(\mathrm{p}<0.001)$, as shown in Table 3. 
Table 3: Chi-squared independent test

\begin{tabular}{|c|c|c|c|c|}
\hline & & \multicolumn{2}{|c|}{ Touristic Accommodation abroad } & \multirow[b]{2}{*}{$\mathrm{p}$-value } \\
\hline & & Not Hosted n(\%) & $\begin{array}{l}\text { Hosted } \\
\mathrm{n}(\%)\end{array}$ & \\
\hline \multirow{2}{*}{$\begin{array}{c}\text { Touristic Accommodation in } \\
\text { Portugal }\end{array}$} & Not Hosted & $19(48.7 \%)$ & $20(51.3 \%)$ & \multirow{2}{*}{$<0.001$} \\
\hline & Hosted & $31(18.6 \%)$ & $136(81.4 \%)$ & \\
\hline
\end{tabular}

Source: Own elaboration based on SPSS output ( $N=206$, due to omitted cases)

To validate RH3 and RH4, a factorial analysis was applied in order to find dimensions that are not directly observable, but maybe able to explain what motivates the tourist from the North of Portugal when travelling in Portugal and abroad.

As for the motivations to travel in Portugal, the factorial analysis (Table 4) showed that the 14 studied initial items were explained in $59.13 \%$ for 4 common factors obtained from a Varimax rotation with Kaiser
Normalization, indicating a reasonable correlation between the items (0.798). Also, the Bartlett's Test of Sphericity showed that the variables under analysis are statistic and significantly correlated (p-value < 0.001). The analysis can explain that the Portuguese tourists' motivations for travelling in Portugal are: Leisure (30.02\%), Attractiveness (10.67\%), Reason for travel $(10.54 \%)$ and Price (7.90\%). Cronbach's alpha is 0.798, indicating good internal consistency reliability.

Table 4: Factorial Analysis

\begin{tabular}{|c|c|c|c|c|}
\hline Factor & Variable included in the factor & Loadings & Eigenvalues & $\begin{array}{c}\% \text { of } \\
\text { explained } \\
\text { variance }\end{array}$ \\
\hline \multicolumn{2}{|c|}{1 (Leisure) } & & 4.20 & 30.02 \\
\hline & History/Culture & 0.740 & & \\
\hline & Nature & 0.684 & & \\
\hline & Gastronomy & 0.648 & & \\
\hline & Hospitality & 0.613 & & \\
\hline & Search for Adventure & 0.565 & & \\
\hline \multicolumn{2}{|c|}{2 (Attractiveness) } & & 1.49 & 10.67 \\
\hline & Accessibility and ease of travel & 0.771 & & \\
\hline & Attractive climate & 0.762 & & \\
\hline & Sun and beach conditions & 0.733 & & \\
\hline & Country's safety & 0.595 & & \\
\hline \multicolumn{2}{|c|}{3 (Reason for travel) } & & 1.48 & 10.54 \\
\hline & $\begin{array}{l}\text { Need (work, visiting family and/or } \\
\text { business) }\end{array}$ & 0.753 & & \\
\hline & Health reasons & 0.661 & & \\
\hline & Attractive airline prices & 0.653 & & \\
\hline \multicolumn{2}{|c|}{4 (Price) } & & 1.11 & 7.90 \\
\hline & Price & 0.799 & & \\
\hline & Accommodation & 0.706 & & \\
\hline Total & & & & 59.13 \\
\hline
\end{tabular}

Source: Own elaboration based on SPSS output 
In order to understand if there are significant differences in each of the factors that motivate tourists to travel in Portugal by joining local accommodation in Portugal (RH3), the Mann-Whitney nonparametric test was used (Table 5).

Table 5: Mann-Withney tests

\begin{tabular}{|c|c|c|c|c|c|}
\cline { 3 - 6 } \multicolumn{2}{|c|}{} & Leisure & Attractiveness & $\begin{array}{c}\text { Travels } \\
\text { Purpose }\end{array}$ & $\begin{array}{c}\text { Price } \\
\text { Accommodation }\end{array}$ \\
\hline Frequency in Local & Yes & $3.84 \pm 0,06$ & $4.26 \pm 0.06$ & $2.52 \pm 0.09$ & $3.63 \pm 0.08$ \\
\cline { 2 - 6 } Accommodation & No & $3.74 \pm 0.07$ & $4.16 \pm 0.07$ & $2.44 \pm 0.08$ & $3.46 \pm 0.09$ \\
\hline & & MW-U & MW-U & MW-U & MW-U \\
\hline & & 7039.500 & 7394.000 & 7039.500 & 7364.500 \\
\hline & & $(0.399)$ & $(0.228)$ & $(0.612)$ & $(0.247)$ \\
\hline
\end{tabular}

Note: MW- U - Mann-Whitney U test

Source: Own elaboration based on SPSS output

As for the motivations to travel abroad, the factorial analysis showed that the 14 studied initial items were explained in $66.49 \%$ for 5 common factors obtained from a Varimax rotation with Kaiser Normalization, indicating a reasonable correlation between the items (0.7368).

Also, the Bartlett's Test of Sphericity showed that the variables under analysis are statistic and significantly correlated (p-value < 0.001). The analysis can explain that the Portuguese tourists' motivations for travelling abroad are: Attractiveness (27.51\%), Hospitality (10.67\%), Price (10.01\%), Leisure (9.48\%) and Reason for Travel (8.21\%), as seen in Table 6. Cronbach's alpha is 0.798 , indicating good internal consistency reliability.

Table 6: Factorial Analysis

\begin{tabular}{|c|c|c|c|c|}
\hline Factor & Variable included in the factor & Loadings & Eigenvalues & $\begin{array}{c}\% \text { of explained } \\
\text { variance }\end{array}$ \\
\hline \multicolumn{2}{|c|}{ I (Attractiveness) } & & 3.85 & 27.51 \\
\hline & Sun and beach conditions & 0.852 & & \\
\hline & Attractive climate & 0.843 & & \\
\hline & Nature/Landscape & 0.664 & & \\
\hline \multicolumn{2}{|c|}{2 (Hospitality) } & & 1.57 & 11.21 \\
\hline & Accommodation & 0.770 & & \\
\hline & Gastronomy & 0.751 & & \\
\hline & Hospitality & 0.712 & & \\
\hline \multicolumn{2}{|c|}{3 (Price and facilities) } & & 1.41 & 10.01 \\
\hline & Price & 0.599 & & \\
\hline & Accessibility and ease of travel & 0.790 & & \\
\hline & Country's safety & 0.647 & & \\
\hline & Attractive airline prices & 0.560 & & \\
\hline \multicolumn{2}{|c|}{4 (Leisure) } & & 1.33 & 9.48 \\
\hline \multicolumn{2}{|c|}{ History/Culture } & 0.671 & & \\
\hline \multicolumn{2}{|c|}{ Accommodation } & 0.768 & & \\
\hline \multicolumn{2}{|c|}{ 5. (Reason for travel) } & & 1.15 & 8.21 \\
\hline & Health reasons & 0.726 & & \\
\hline & $\begin{array}{l}\text { Need (work, visiting family and/or } \\
\text { business) }\end{array}$ & 0.854 & & \\
\hline Total & & & & 66.49 \\
\hline
\end{tabular}

Source: Own elaboration based on SPSS output 
Concerning RH4, the only validated factor is "Leisure" and may, in fact, interfere in the choice of a local accommodation abroad or not, as seen in Table 7 . The remaining motivating factors for travelling abroad are significantly different between the people who joined and those who did not join the local accommodation abroad.

Table 7: Mann-Withney U tests

\begin{tabular}{|c|c|c|c|c|c|c|}
\hline & & Attractiveness & $\begin{array}{l}\text { Hospitality } \\
\text { and } \\
\text { Gastronomy }\end{array}$ & $\begin{array}{l}\text { Price and } \\
\text { facilities }\end{array}$ & Leisure & $\begin{array}{c}\text { Reason for } \\
\text { travel }\end{array}$ \\
\hline \multirow{5}{*}{$\begin{array}{c}\text { Frequency in Local } \\
\text { Accommodation - } \\
\text { abroad }\end{array}$} & Yes & $3.75 \pm 0.09$ & $3.22 \pm 0.08$ & $3.67 \pm 0.07$ & $4.18 \pm 0.07$ & $2.22 \pm 0.10$ \\
\hline & No & $3.76 \pm 0.10$ & $3.16 \pm 0.09$ & $3.61 \pm 0.08$ & $3.65 \pm 0.08$ & $2.07 \pm 0.10$ \\
\hline & & MW-U & MW-U & MW-U & MW-U & MW-U \\
\hline & & 5295.000 & 5595.000 & 5805.500 & 7668.500 & 6079.500 \\
\hline & & $(0.477)$ & $(0.973)$ & $(0.660)$ & $(0.000)$ & $(0.282)$ \\
\hline
\end{tabular}

\section{Conclusion}

The study seems to point out that the adhesion of tourists from the north of Portugal to local accommodation in Portugal is related to the adhesion to local accommodation abroad, with the existence of a relationship between the demand for local accommodation in Portugal and abroad. It was found that $63 \%$ of the respondents who stayed in local accommodation in Portugal also stayed in local accommodation abroad, and $69.4 \%$ who were not staying in local accommodation in Portugal also did not stay in local accommodation abroad (Table 2). The national tourist's perception of local accommodation does not change depending on the location (Portugal/abroad).

The adhesion of tourists from the north of Portugal to touristic accommodation in Portugal is related to the adhesion to touristic accommodation abroad and there is a relationship between the demand for touristic accommodation in Portugal and abroad. In fact, $81.4 \%$ of the respondents who stayed in touristic accommodation in Portugal also stayed in touristic accommodation abroad and $48.7 \%$ who were not lodged in touristic accommodation in Portugal also did not stay in touristic accommodation abroad. This reinforces the argument that the perception of the national tourist about touristic accommodation does not change depending on the location (Portugal/abroad).

The adhesion to local accommodation in Portugal is not related to the reasons for the trip/travel. This means that none of the four travel motivation groups appear to interfere with the demand for local accommodation. Regarding the adhesion to local accommodation abroad, only Leisure appears to be a relevant motivation group. The other remaining motivation groups were not validated.

As a final conclusion, this study adds knowledge about local accommodation, a new type of accommodations that is nowadays rising. It was possible to portray the sample through an exploratory descriptive analyses and statistical tests, demonstrating the behaviours, motivations and influences of the national tourist in the northern part of Portugal when adhering to local accommodation in Portugal and abroad. The study aims to support local accommodation owners and managers who need strategic information to attract and build loyalty with national tourists. 


\section{Acknowledgment}

Project "TURNOUT: Desenvolvimento do Turismo Outdoor da Região Norte de Portugal", with the reference POCI-01-0145FEDER-032289, and funded by the European Regional Development Fund (FEDER) (through the Operational Programme 'Innovation and competitiveness') and by the Portuguese Foundation for the Development of Science and Technology (FCT), of the Ministry of Science, Technology and Higher Education. This work is also, funded by National Funds through the Foundation for Science and Technology under the project UID/GES/04752/2019.

\section{References}

- Bardhi, F. and Eckhardt, G. M. (2012). Access-Based Consumption: The Case of Car Sharing, Journal of consumer research, 39(4), 881-898.

- Bellotti, V., Ambard, A., Turner, D., Gossmann, C., Demkova, K., and Carroll, J. M. (2015). A muddle of models of motivation for using peer-to-peer economy systems, Paper presented at the Proceedings of the 33rd Annual ACM Conference on Human Factors in Computing Systems.

- Blythe, J. (2005). Essentials of marketing (Third ed.). Pearson Education: University of Glamorgan.

- Botsman, R. (2015). Defining the sharing economy: what is collaborative consumption-and what isn't. Retrieved from https://www.fastcompany. com/3046119/defining-the-sharingeconomy-what-iscollaborativeconsumption-and-whatisnt.

- Botsman, R. and Rogers, R. (2010), What's Mine Is Yours: The Rise of Collaborative Consumption. Harper Collins Publisher, USA.

- Chang, W. J. and Katrichis, J. M. (2016), A literature review of tourism management (1990-2013): a content analysis perspective. Current Issues in Tourism, 19(8), 791-823.
- Chetthamrongchai, P. (2017), 'The Influence of Travel Motivation, Information Sources and Tourism Crisis on Tourists' Destination Image. Journal of Tourism \& Hospitality, 6(2).

- Chhabra, D., Healy, R. and Sills, E. (2003), 'Staged authenticity and heritage tourism', Annals of Tourism Research, 30, 702-719.

- Freitag, P. M., and Haywood, J. (2015), Digging the core of airbnb's big apple data Hotel News Now. Retrieved from http://www.hotelnewsnow.com/Article /16395/Digging-to-the-core-of-AirbnbsBig-Apple-data.

- Foxall, G. R. (1990), Consumer Psychology in Behavioural Perspective. Routledge, London.

- Foxall, G. R. and Goldsmith, R. E. (1994), Consumer Psychology for Marketing. Routledge, London

- Gansky, L. (2012). The mesh: Why the future of business is sharing. New York, US: Portofolio Trade, Penguin Group.

- Guttentag, D. (2015), Airbnb: disruptive innovation and the rise of an informal tourism accommodation sector. Current Issues in Tourism, 18(12).

- Hamari, J., Sjöklint, M. and Ukkonen, A. (2016), The Sharing Economy: Why People Participate in Collaborative Consumption. Journal of the Association for Information Science and Technology, 67, 2047-2059.

- Haywood, J., Hoyt, A., Wilson, C., Hennis, S. and Alvarado, C. (2016), 'STR: Airbnb's impact minor on Manhattan hotels. Hotel News Now'. Retrieved from http:// www.hotelnewsnow.com/Articles/2963 9/STR-Airbnbs-impact-minoronManhattan-hotels

- International Tourism Highlights, 2019 Edition. (2019), World Tourism Organization.

- Instituto Nacional de Estatística Estatísticas do Turismo: 2018. Lisboa: INE, 2019.

- International Finance Corporation (2017). Twenty Reasons Sustainable Tourism Counts for Development. Tourism 
for Development knowledge series. World Bank, Washington, DC.

- Joseph, A. (2013). Tourism Principles, Policies \& Practices, (MBA - Tourism), Pondicherry University.

- Kisi, N. (2019). A Strategic Approach to Sustainable Tourism Development Using the A'WOT Hybrid Method: A Case Study of Zonguldak, Turkey. Sustainability, 11(964), 2-19.

- Kotler, P. (2000). Marketing management (10th ed.): Praha: Grada Publishing.

- Kotler, P. and Amstrong, G. (2011), Principles of marketing (Vol. 14th edition).

- Lamberton, C. P. and Rose, R. L. (2012). When is ours better than mine? A framework for understanding and altering participation in commercial sharing systems, Journal of Marketing, 76(4), 109-125.

- Leslie, D. (2000). Souvenirs and Forgetting: Walter Benjamin's MemoryWork (C. B. a. J. A. e. M. M. M. Kwint Ed.): Oxford: Berg.

- Lewis and Bridger. (2000). The Soul of the New Consumer: Authenticity - what We Buy and why in the New Economy: Nicholas Brealey.

- Lopez, c. (2020). Finance, Competitiveness and Innovation Global Practice, February 2020. Policy Research Working Paper, 9147. World Bank Group.

- Mahadevan, R. (2018), Examination of motivations and attitudes of peer-topeer users in the accommodation sharing economy. Journal of Hospitality Marketing \& Management, 27(6), 679692.

- Möhlmann, M. (2015), Collaborative consumption: determinants of satisfaction and the likelihood of using a sharing economy option again. Journal of Consumer Behaviour, 14(3), 193-207.

- Mullen, B. and Johnson, C. (1990), The psychology of Consumer Behavior. Lawrence Erlhaum Associates, Inc. Publishers, New Jersey.

- Mwinuka, O. H. (2017), Reviewing the role of tourism marketing in successful sustainable tourist destinations. African Journal of Hospitality, Tourism and Leisure, 6(2), 1-11.

- Oliveira, E. (2014), The tourism potential of Northern Portugal and its relevance for a regional branding strategy. Advances in Hospitality and Tourism Research, 2 (2), 54-78.

- Pavlovic, D. (2016), Tourist Perception as Key Indicator of Destination Competitiveness. Journal for Social Sciences, 14(1), 37-48.

- Petropoulos, G. (2017). An economic review of the collaborative economy. Policy Contribution, 5.

- Portugal, T. (n.d.), Retrieved from www.turismodeportugal.pt

- Pruthi, R. K. (2004). International Tourism: Potential Measurement and Prospects. New Dehli: Rajat Publications.

- Robison, J. P. (1976). A Geography of Tourism, MacDonell and Evans, Lda.

- Sacks, D. (2011), The sharing economy Fast Company, Retrieved from http://www.fastcompany.com/1747551 /sharing-economy

- Sharpley, R. (2014), Host perceptions of tourism: A review of the research, Tourism Management, 42, 37-49.

- Šimková, E. (2014), Psychology and its Application in Tourism. Procedia - Social and Behavioral Sciences, 114, 317-321.

- Tussyadiah, I. and Pesonen, J. (2015). Impacts of Peer-to-Peer Accommodation Use on Travel Patterns, Journal of Travel Research, 55(8), 1022-1040.

- Tussyadiah, I. and Zach, F. (2015). Hotels vs. Peer-to-Peer Accommodation Rentals: Text Analytics of Consumer Reviews in Portland, Oregon. http://dx.doi.org/10.2139/ssrn.259498 5.

- Vainikka, B. (2015). Psychological factors influencing consumers behaviour. S Business Management Thesis, Centria University of Applied Sciences.

- Weaver, D. V. and Lawton, L. (2010). Tourism management/David Weaver, Laura Lawton. (Vol. 4th ed.). 
- Wroten, B. (2017), Blockchain holds promise, unknowns for hotel industry, Hotelnewsnow, 8(11).

- WTTC (2017). Global economic impact and issues. World Travel and Tourism Council.

- WTTC (2020). Global economic impact and issues. World Travel and Tourism Council.

- Xie, and Kwok (2017). The effects of Airbnb's price positioning on hotel performance, International Journal of Hospitality Management, 67, 174-184.

- Zervas, G., Proserpio, D. and Byers, J. W. (2017). The Rise of the Sharing Economy: Estimating the Impact of Airbnb on the Hotel Industry, Journal of Marketing Research, 54(5), 687-705. 